\title{
US health spending up; medicare expanded
}

With health spending in the United States projected to continue its rise, the Bush Administration is opening the federal coffers to provide more publicly funded prescription drugs. Some, however, think it may not do much good.

By 2014, health spending is projected to total $18.7 \%$ of GDP, compared with $15.3 \%$ in 2003. That's an increase from $\$ 1.8$ trillion per year to $\$ 3.6$ trillion, according to a report issued by the Centers for Medicare and Medicaid Services. By comparison, Canada spends $10 \%$ of GDP on health.

Driving the need for more cash is the development and use of medical technologies such as CT scanners and MRIs and the introduction of new and more expensive pharmaceuticals, as well as the rapid growth in surgical procedures, according to the Organisation for Economic Co-operation and Development.

These increases are squeezing on public budgets in the US. A major shift in spending will occur in 2006, when Medicare reform ushers in a new era of prescription drug payment. Medicare, a federally funded health care plan for Americans over the age of 65 and those on disability, now accounts for only $2 \%$ of total spending on prescription drugs. By 2014, it is expected to account for $28 \%$.

The new legislation makes publicly funded prescription drug coverage available to every senior for the first time in American history. Seniors will be represented by private insurance companies, commissioned by the federal government.

The Bush team advertises that bartering between big pharma- ceutical companies and the insurance companies will drive down the price of prescription drugs in the US, but some experts disagree. Due to complex premium calculations and the abolition of various state-run programs, lowincome seniors may end up paying more for their prescriptions under the new system than they ever did before.

"They've been bartering on behalf of lots of groups for the last 10 years, and what's happened to the price of prescription drugs?" asks Theodore Marmor, a health policy analyst with Yale University.

"The program has a benefit structure that is completely screwy. This bill is a complex piece of legislation. For chronically ill people, there will be a maintained demand to get cheaper drugs from Canada." Michelle Catton, Ottawa

\section{Global Health}

\section{New malaria combination cheaper and easier to take}

At least 50 million malaria patient a year could benefit from the first new drug developed by the 2-year-old Drugs for $\mathrm{Ne}$ glected Disease initiative (DNDi). A patent-free, fixeddose formulation of combined artesunate-amodiaq antimalarial will be available in early 2006 .

Unlike existing antimalarials, the new formulation combines 2 drugs in 1 tablet. Adult patients need only 2 tablets per day for 3 days, instead of 8 with current drugs.

"The big advantage is that it is simpler to take," says DND $i$ Executive Director Dr. Bernard Pécoul.

The new drug is also cheaper: less than US\$1 to treat an adult compared with US\$2.5 for current combinations. In addition, current combinations cannot be used by children under 5 ; the new formulation can be used at 6 months of age.
Malaria is present in more than 100 countries, threatening $40 \%$ of the world's population and killing up to 2 million people annually, $90 \%$ of them in sub-Saharan Africa.

Sanofi-Aventis, the world's third largest pharmaceutical company, will register, manufacture and sell the drug at cost to NGOs, the public sector and international organizations. "The advantage of Sanofi-Aventis is that they are working in Africa already," says Pécoul. The company has agreed to donate $3 \%$ of private sector sales revenue to DND $i$.

The new formulation is generic, "so if it's used widely in Africa, or say, Indonesia, they can produce it themselves," says Pécoul.

With the increasing parasite resistance to antimalarials, particularly chloroquine, WHO recommends combining 2 anti-

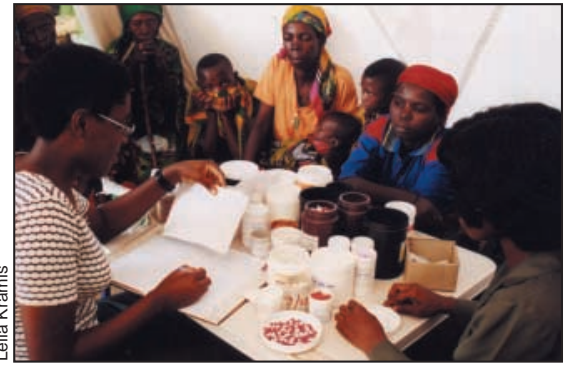

Testing people for malaria at the DNDi/MSF program in Kigova, Burundi.

malarials, 1 being a derivative of artemisinin.

$\mathrm{DND} i$ is supported by Médecins Sans Frontières, 5 public sector institutions and the UNDP/World Bank/WHO's Special Programme for Research and Training in Tropical Diseases. Currently, 18 projects are underway; a second antimalarial, targeted to resistant strains in Latin America and South East Asia, should also be ready in early 2006. - Barbara Sibbald, CMAJ 